\title{
Effect of Age, Gender and Season on Thyroid Hormones Status in Children of East Delhi- A Hospital Based Study
}

\author{
Pradeep Kumar Dabla $^{1,2}$, Shikha Sharma ${ }^{1 *}$ and Nakshi Sinha ${ }^{1}$ \\ ${ }^{1}$ Department of Biochemistry, Chacha Nehru Bal Chikitsalya, New Delhi, India.
}

${ }^{2}$ G.B Pant Institute of Postgraduate Medical Education \& Research, Associated to Maulana Azad Medical College, New Delhi, India.

Received: March 15, 2018; Accepted: April 03, 2018; Published: April 06, 2018

*Corresponding author: Shikha Sharma, Department of Biochemistry, Chacha Nehru Bal Chikitsalya Hospital, Associated to Maulana Azad Medical College, New Delhi, India, E-mail: drshikhacnbc@gmail.com

\section{Abstract}

Background: Thyroid hormones are the most commonly prescribed tests in the clinical set up. Variations are observed in individuals of different age, sex, race and nutritional status. However few studies describe these changes in children. The aim of the present study was to evaluate thyroid hormones in children of East Delhi with respect to gender, age and season.

Methods: The study included 850 children up to 12 years of age of both genders who attended the hospital for thyroid hormone analysis. Subjects suffering from thyroid disorders or those on medication affecting hormone status were excluded from the study. Non-fasting venous samples were collected and serum FT3, FT4 and TSH levels were estimated by chemiluminesence method. Statistical analysis was done by using unpaired t-test and ANOVA.

Results: TSH levels were found to be statistically higher in the female subjects $(p=0.049)$. On evaluating hormones age wise FT3 levels were found to increase significantly with age $(p=0.000)$ whereas FT4 and TSH levels significantly declined with age ( $p=0.000$ and $p=0.039$ ). Significant seasonal variation in hormones was also observed.

Conclusions: Our results shows that thyroid hormone levels change markedly in childhood. Variation in thyroid hormone levels has to be kept in mind during evaluation and treatment of thyroid disorders in children.

Keywords: thyroxine (T4); tri-iodothyronine(T3); thyroid stimulating hormone (TSH); thyroid hormones; age variation; gender variation; seasonal variation; children

\section{Introduction}

The thyroid gland is an important endocrine gland crucial for the growth and development of children. Its deficiency is associated with severe physical and mental impairment. The gland is responsible for the secretion of two metabolically active hormones which include tetra-iodo-thyronine or thyroxin (T4) and tri-iodo-thyronine (T3) with concentrations of $93 \%$ and $7 \%$ respectively [1]. T3 is four times more potent than T4 but with a shorter half life and is present in lesser concentration in the blood. The gland is regulated by the anterior pituitary hormone TSH whose secretion is further under control by the hypothalamus.
Iodine is required for hormone synthesis. Adequate dietary intake of iodine is therefore essential and depends on the growth, body weight, age, sex and nutritional status of the individual. Climate and various disease conditions may also affect the requirement of iodine [2]. In normal individuals the thyroid hormones show variations with respect to age, sex, nutrition and race[3-5]. The relationship of the gland with aging is of special interest because of the importance of the organ in regulating the rates of various body functions. Gradual increase in the autonomous tissue with age makes the individual more susceptible to thyroid problems. The concentration of the hormones decreases with age in both sexes however the drop is observed to be more in the female than males [6]. Interpretation of thyroid function tests can be difficult at times. The correct understanding of these physiologically related changes is important to clinically differentiate from subclinical thyroidal illness or non-thyroidal disease and provide appropriate and timely treatment. Age and gender dependent variation among children and adolescents has been studied by many workers, however with contradictory findings [7, 8, 9]. In view of these inconclusive findings the present study was undertaken to evaluate the physiological changes in thyroid hormones in children of East Delhi.

\section{Materials and Methods}

The present cross sectional study was conducted in the Department of Biochemistry at Chacha Nehru Bal Chikitsalya Hospital, New Delhi. Children up to 12 years of age who had attended the hospital for thyroid hormone test for period of one year were included in the study. The study was approved by the scientific ethical committee and informed consent was taken from all patients. Secondary data on age, gender, season, FT3, FT4 and TSH level were analyzed. Children were excluded if they had any personal or family history of thyroid disease, goitre, hypothyroidism, hyperthyroidism or history of intake of medication which could affect the thyroid status. Also patients who had fever and chronic illness like nephrotic syndrome, renal failure, malabsorption disorders like celiac disease or malignancy etc were excluded from the study. In this way a total of 350 from 1200 subjects were excluded from the study. Informed consent was taken from the remaining 850 subjects. The patients were 
classified according to their age into neonates ( $0-1$ month), infants (1-12 months), preschool children (1-5 yrs) and school going and adolescent group (6-12 yrs); males and females according to their sex. Seasons were classified as winter (Nov-Jan), spring (Feb-Apr), summer (May-July) and autumn (Aug-Oct) according to their visit to the laboratory. The data were organised to know the variations of thyroid hormones in different age, sex and seasons. Blood samples were obtained from ante-cubital vein of subjects under aseptic conditions. The samples of the newborns were collected between 4 th to 7 th day after birth. $3 \mathrm{ml}$ of venous blood was collected and allowed to clot. Serum was separated by centrifugating at $2000 \mathrm{rpm}$ for 5 mins. Samples were analyzed for FT3, FT4 and TSH by chemiluminiscence method on Access-2 Beckman Coulter analyser. Analysis of thyroid hormones in male and female subjects was done by using student's unpaired t-test. Whereas One-way analysis of variance (ANOVA) was used to compare thyroid hormones in children of different age groups along with comparison in different seasons. A p-value of $<0.05$ was considered as statistically significant. Calculations were done using SPSS software, version 15.0 for Windows.

\section{Results}

In the present study FT3, FT4 and TSH concentrations were measured in serum samples of all evaluable study subjects. The mean \pm SD for FT3 in our study subjects was $3.43 \pm 1.07 \mathrm{pg} / \mathrm{mL}$ for FT4 $0.93 \pm 0.51 \mathrm{ng} / \mathrm{dL}$ and $3.44 \pm 2.75 \mu \mathrm{IU} / \mathrm{mL}$ for TSH.

(Table 1) shows the segregation of subjects according to different age groups. Males made up $53.5 \%$ of the study group whereas females $46.5 \%$ respectively. On evaluating the impact of gender on thyroid hormone levels (Table 2), a significant elevation of TSH was found in females ( $p=0.049$ ). FT4 levels were slightly higher in females however the difference was not statistically significant. No significant difference was found in levels of FT3 in male and female subjects.

\begin{tabular}{|l|c|c|}
\hline \multicolumn{1}{|c|}{ Table 1: Classification of subjects in different age groups } \\
\hline Age & Male & Female \\
\hline $0-1$ month & $56(12.3 \%)$ & $43(10.8 \%)$ \\
\hline $1-12$ months & $77(16.9 \%)$ & $53(13.4 \%)$ \\
\hline $1-5$ years & $139(30.5 \%)$ & $105(26.5 \%)$ \\
\hline 6-12 years & $183(40.2 \%)$ & $194(49.1 \%)$ \\
\hline Total & $455(53.5 \%)$ & $395(46.5 \%)$ \\
\hline
\end{tabular}

Table 2: Thyroid hormones in subjects of different gender

\begin{tabular}{|c|c|c|c|}
\hline Gender & FT3 & FT4 & TSH \\
\hline Male & $3.4 \pm 1.08$ & $0.91 \pm 0.38$ & $3.26 \pm 2.31$ \\
\hline Female & $3.37 \pm 1.09$ & $0.94 \pm 0.62$ & $3.63 \pm 3.15$ \\
\hline P-Value & 0.687 & 0.388 & 0.049 \\
\hline
\end{tabular}

Hormone levels were also compared in children belonging to different age groups. FT3 levels were found to be lowest amongst neonates and highest levels were seen in children between 1-5 years. Levels were similar in children between 1-12 months and 6-12 years of age. There was a statistically significant variation in
FT3 level $(\mathrm{p}=0.000)$ in different age groups on applying ANOVA test (Table 3 and Graph 1). On the other hand levels of FT4 were highest amongst neonates. Levels in the remaining groups

Table 3: Thyroid hormones in subjects of different age groups

\begin{tabular}{|c|c|c|c|}
\hline Age & FT3 & FT4 & TSH \\
\hline 0 -1mth & $2.45 \pm 0.91$ & $1.10 \pm 0.5$ & $3.42 \pm 2.61$ \\
\hline $1-12 \mathrm{mth}$ & $3.41 \pm 1.01$ & $0.89 \pm 0.37$ & $3.28 \pm 2.7$ \\
\hline 1-5yrs & $3.58 \pm 1.02$ & $0.88 \pm 0.36$ & $3.04 \pm 2.13$ \\
\hline 6-12yrs & $3.44 \pm 1.06$ & $0.93 \pm 0.51$ & $3.57 \pm 2.07$ \\
\hline p-value & $\mathrm{p}=0.000$ & $\mathrm{p}=0.000$ & $\mathrm{p}=0.039$ \\
\hline
\end{tabular}

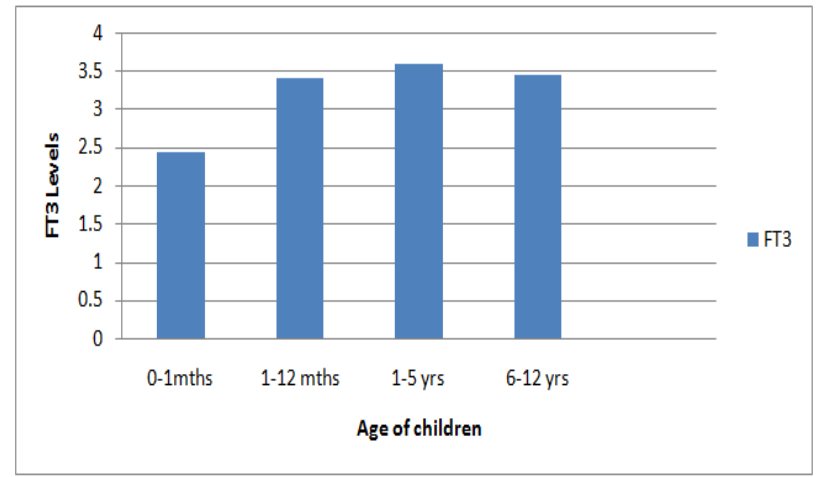

Graph 1: FT3 levels in different age groups

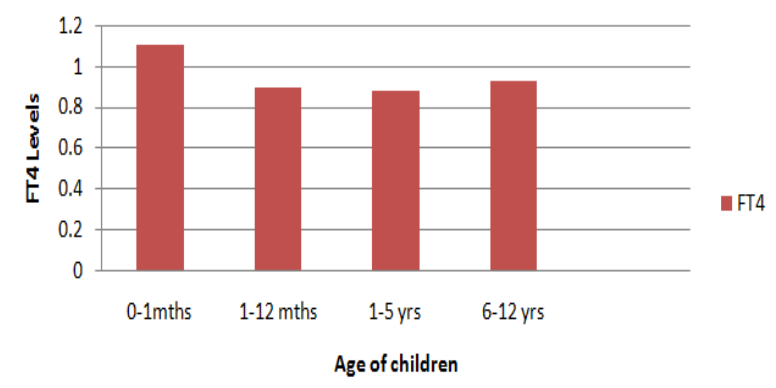

Graph 2: FT4 levels in different age groups

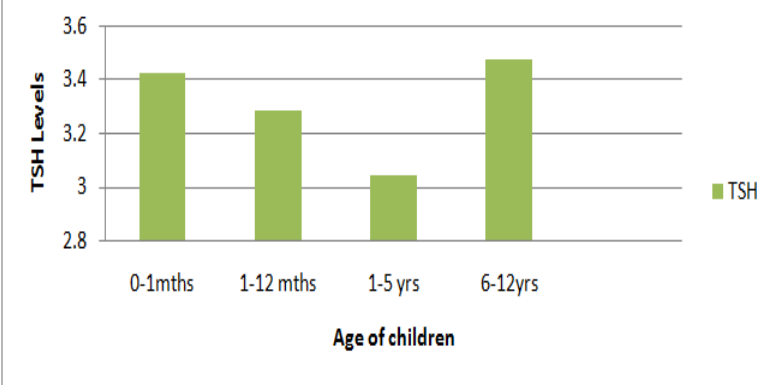

Graph 3: TSH levels in different age groups

remained stable with FT4 levels being slightly higher in 6-12 year group. A statistically significant variation in FT4 level ( $\mathrm{p}=0.000)$ was also seen in different age groups on applying ANOVA test (Table 3 and Graph 2). TSH level was found to be highest in 
children of 6-12 years age. Neonates showed higher levels of TSH followed by a decline in the first year of life and up till 5 years. A statistically significant variation in TSH level $(p=0.039)$ was also seen in different age groups on applying ANOVA test (Table 3 and Graph 3).

On evaluating hormone levels in male and female subjects in different age groups, FT3 and TSH levels were found to be higher in the female subjects in all age groups. FT4 levels were higher in the female subjects amongst the neonates as well as in the 6-12 years age group. However these differences were not statistically significant as shown in Table.4.
The hormonal changes in different seasons are shown in Table.4. TSH levels were highest in the winter season and lowest during the monsoon. In summer and autumn months levels were almost equal. A statistically significant variation in TSH level ( $p$ $=0.045$ ) was seen in different seasons on applying ANOVA test. FT3 levels were found to be highest in the summer and lowest in autumn. Levels were similar during the monsoon and winter season. A statistically significant variation in FT3 level $(p=0.000)$ was seen in different seasons on applying ANOVA test (Table.4). FT4 levels were highest in the winter followed by the monsoon season. Levels in summer and autumn were similar. A statistically significant variation in FT4 level $(p=0.018)$ in different seasons was also seen on applying ANOVA test.

Table 4: Thyroid hormones in male and female subjects of different age groups

\begin{tabular}{|c|c|c|c|c|c|c|c|c|r|}
\hline Age & \multicolumn{3}{|c|}{ FT3 } & \multicolumn{3}{c|}{ FT4 } & \multicolumn{3}{c|}{ TSH } \\
\hline & Male & Female & p-value & Male & Female & p-value & Male & Female & p-value \\
\hline $0-1$ mth & $3.43 \pm 1.08$ & $3.44 \pm 1.06$ & 0.961 & $0.92 \pm 0.38$ & $0.94 \pm 0.63$ & 0.851 & $3.29 \pm 2.34$ & $3.63 \pm 3.18$ & 0.541 \\
\hline $1-12$ mths & $3.35 \pm 1.10$ & $3.58 \pm 1.00$ & 0.232 & $0.95 \pm 0.59$ & $0.91 \pm 0.36$ & 0.664 & $3.36 \pm 2.47$ & $3.59 \pm 3.14$ & 0.642 \\
\hline $1-5$ yrs & $3.43 \pm 1.07$ & $3.51 \pm 1.05$ & 0.561 & $0.93 \pm 0.51$ & $0.89 \pm 0.36$ & 0.492 & $3.44 \pm 2.76$ & $3.56 \pm 3.05$ & 0.754 \\
\hline $6-12$ yrs & $3.43 \pm 1.08$ & $3.44 \pm 1.05$ & 0.933 & $0.92 \pm 0.39$ & $0.95 \pm 0.63$ & 0.584 & $3.32 \pm 2.35$ & $3.64 \pm 3.17$ & 0.271 \\
\hline
\end{tabular}

Table 5: Thyroid hormones in subjects in different seasons

\begin{tabular}{|c|c|c|}
\hline Seasons & FT3 & FT4 \\
\hline Summer (N=230) & $3.64 \pm 1.09$ & $0.89 \pm 0.49$ \\
\hline Monsoon (N=210) & $3.26 \pm 1.04$ & $0.94 \pm 0.52$ \\
\hline Autumn (N=220) & $3.16 \pm 0.89$ & $0.89 \pm 0.51$ \\
\hline Winter (N=190) & $3.25 \pm 0.98$ & $1.03 \pm 0.52$ \\
\hline p-value & $\mathrm{p}=0.000$ & $\mathrm{p}=0.018$ \\
\hline
\end{tabular}

\section{Discussion}

India is a vast sub-tropical country with differences in its ethnic background, topography and iodine nutrition. Thyroid hormones are crucial for the growth and development of children. Their biological activity in target cells is determined by the intracellular concentration of T3, which is further dependent upon the circulating levels of T3 and T4 [10]. With an increase in age a decline in thyroid function is observed [11]. The present study was conducted to evaluate the effect of gender, age and season on thyroid function tests (FT3,FT4 and TSH) in children. Our study showed a significant difference in the value of TSH (Table 2) in male and female subjects. This observation was in accordance by a study by Parra et al [8] that in childhood and adolescence sex associated variations in thyroid hormone concentrations may occur. Girls mature at an earlier chronological age than boys. This may represent a partial response of the body to the different qualitative and quantitative energy needs in girls as compared to boys, consecutive to the differences in body composition first appearing at the time of puberty [8]. On evaluating hormone levels in different age groups, FT3 levels were found to be lowest in the neonates followed by increase in level from one month till five years of age and a decline in the 6-12 years age group (Table 3). Immediately after birth TT3 levels are high due to maternal oestrogen induced increase in thyroxine-binding globulin (TBG). In a study by Jacobsen et al [12] FT3 levels were found to increase by $50-70 \%$ in full term infants and reached a maximum value by 50-79 days of life. Levels also markedly increase during early infancy and childhood and tend to decline during adolescence [11]. In the present study also FT3 value in the 6-12 years age group fell to $3.44 \mathrm{ng} / \mathrm{mL}$ from $3.58 \mathrm{ng} / \mathrm{mL}$ in children (1-5 years). Similar values of progressive decrease of T3 levels fom childhood to adolescence have in observed in several studies $[11,13]$. The increased metabolic activity during infancy and childhood may lead to increased peripheral utilisation of thyroid hormones [14]. Our study showed a progressive decline in the FT4 concentration up to 5 years of age, with mean FT 4 of $1.10 \mathrm{ng} / \mathrm{dL}$ in neonates, 0.89 $\mathrm{ng} / \mathrm{dL}$ in infants, $0.88 \mathrm{ng} / \mathrm{dL}$ in children between 1-5 years and $0.93 \mathrm{ng} / \mathrm{dL}$ in 6-12 years age group. At birth TT4 levels are high due to maternal oestrogen induced increase in TBG. Jacobsen et al [12] showed serum T4 levels to decrease by $20 \%$ during the first month of life. Levels decline gradually till 15 years of age. This was in contrast to our study in which we found a decline in FT4 till five years of age followed by an increase. On the other hand a Chinese study indicated that the mean serum thyroxin concentration was high in newborns for up to seven days which reduced in the preschool ages within a few months [15]. Other studies in France [16, 
$17,18]$ indicated that there was no alteration in mean T4 levels between the ages of one month and 2 years, which is different from the results of the Chinese study. Both studies have mostly been carried on in subjects up to 2 years of age and contradict each other, but rely on a key point that serum T4 levels gradually decrease as the children get older. The common key point in the above studies was also found in our investigation. In the present study mean TSH levels in neonates was $3.42 \mu \mathrm{IU} / \mathrm{mL}$. TSH levels surge immediately within 30 minutes of birth from 60-700 $\mu \mathrm{IU} /$ $\mathrm{mL}[19]$ to decline back by 3 days and reach normal adult values after few weeks of life. The mean TSH level in infancy was 3.28 $\mu \mathrm{IU} / \mathrm{mL}$ whereas in $1-5$ years age group was $3.04 \mu \mathrm{IU} / \mathrm{mL}$ which increased to $3.47 \mu \mathrm{IU} / \mathrm{mL}$ in the age group of 6-12 years. Our findings were similar to a study by A. Dambal et al [20]. A prepubertal surge of TSH between 9-9.5 years of age may account for this finding [7]. No sex variations were observed for any of the thyroid hormones in different ages of our subjects under study. This finding was similar to a study by Elmlinger [21] et al, but in contrast to a study by Hubner [22] and his co-workers who found sex specific effects on FT3 residuals in the age group of 11-14 years. The effect of seasons on thyroid hormones FT3, FT4 and TSH was also observed. TSH levels were highest in the winter and lowest during the monsoon season. TSH levels estimated equal in summer and autumn months. FT3 levels were found to be highest in the summer and lowest in autumn whereas similar levels detected during the monsoon and winter season. FT4 levels were highest in the winter and monsoon seasons with winter values being detected slightly higher. FT4 levels in summer and autumn were similar. This variation observed may be due to the effect of cold which may accelerate the peripheral metabolism of thyroid hormones during the winter months and therefore lead to increase in levels of TSH and FT4. Seasonal changes therefore also lead to variations in levels of thyroid hormones. Our findings were in accordance to studies of Khan et al [23] and Chaurasia et al [24].

\section{Limitations of the present study}

The main limitation in our study was that, it comprised of a hospital based population. Physiological variations determined from a large cohort of healthy subjects may give more insight. However due to ethical and practical considerations in children, hospital data was used to conduct the present study which will serve as a base for further large scale evaluations. Since reference groups are based in a hospital, our results may slightly diverge from similar population. This concern was addressed by excluding subjects with diagnosis and medication affecting thyroid functions. Further studies are also required on a larger sample size in adolescents to investigate the significance of gender on thyroid hormone levels.

\section{Conclusion}

Our results coroborate with those of previous studies showing that thyroid hormone levels change markedly in childhood. Variations in thyroid hormones with respect to age, gender and season should be carefully assessed in each country and even each state of each country to prevent any misdiagnosis with respect to thyroid hormones which are vital for growing children.

\section{References}

1. Guyton WC, Hall IE. A Textbook of Medical Physiology. Philadelphia; W B Saunders \& Co: 1996.

2. WHO, Global prevalence of iodine deficiency of iodine deficiency disorder, MDIS Working paper. 1993.

3. Blanco AC, Dehesa EM, Longas AF, Aizpun JIL, Lazaro RM. Reference values for thyroid hormones, thyrotropin and thyroglobulin in healthy children of Zargova. Anales Espanoles De Pediatria. 1995;51(4):361368.

4. Marwaha RK, Tandon N, Desai A, Kanwar R, Grewal K, Aggrawal R. Reference range of thyroid hormones in normal Indian school age children. Clin Endocrinol(Oxf). 2008;68(3):369-374. Doi: $10.1111 / \mathrm{j} .1365-2265.2007 .03048 . x$

5. Jean D, Wilson MD, Daniel W, Foster MD. William's Textbook of Endocrinology, 8th Ed, Philadelphia; WB. Saunders Co: 1992.

6. Razzak, MA. Effect of Age and Sex on Thyroid Function Tests Established of norms for the Egyptian Population in Development in Radioimmunoassay and Related Procedures International Atomic Energy Agency. 1992;:.353-358.

7. Michand P, Foradori A Rodriguez-Portales JA et al. A prepubertal surge of thyrotropin precedes an increase in thyroxin and 3, 5, 3 -triiodothyronine in normal children. J Clin Endocrinol Metab.1991;72:979-81.

8. Parra S. Villalpando E. Junco B. Urquieta S. Alatorre and G. GarcíaBulnes. Thyroid gland functions during childhood and adolescence. Change in Serum TSH,T4,T3,Thyroxinbinding globulin, reverse T3, free T4 and T3 concentration. Acta Endocrinol. 1980;93(3):306-341.

9. Chanione JP, Toppet V, sLagasse R, Speh M, Delange F. Determination of thyroid volume by ultrasound from the neonatal period to late adolescent. Euro Pediatr. 1991;150(6):395-399.

10. AF. Radicioni MD, N Tahani, Spaziani A, Anzuini C, Piccheri A. Semeraro L. Tarani A. Lenzi. Reference ranges for thyroid hormones in normal Italian children and adolescents and overweight adolescents. Journal of Endocrinological Investigation. 2013;36(5):326-330.

11. Westgren $U$, Burger A, Ingemansson $S$, Melander A, Tibblin S, Wåhlin E. Blood levels of 3, 5, 3'-triiodothyronine and thyroxine: differences between children, adults, and elderly subjects. Acta Med Scand. 1976;200(6):493-495.

12. Jacobsen BB, Hummer L. Changes in serum concentrations of thyroid hormones and thyroid hormone-binding proteins during early infancy. Studies in healthy full term, small-for-gestational age and preterm infants aged 7 to 240 days. Acta Paediatr Scand. 1979;68(3):411-418

13. Hishikawa $M$, Inada $M$, Naito $K$, Ishii $H$, Tanake $K$, Mashio $Y$, et al. Age related changes of serum 3,3'- iodothyronine, 3,5'-di iodothyronine and 3,5- diiodothyronine concentration in man. J Clin Endocrinol Metab. 1981;52:517-522.

14. Dunger DB, Perkins JA, Jowett TP, Edwards PR, Cox LA, Preece MA, et al. A longitudinal study of total and free thyroid hormones and thyroxine binding globulin duing normal puberty. Acta Endocrinol (Copenh). 1990;123(3):305-310.

15. Tsai WY. Lee JS. Chou YH. Yau KI. Thyroid Function in normal neonates and in fants. 1994;35(4):261-265. 
16. Liappis N, and A Starke. Reference Value for the Concentration of free thyroxine and free triiodothyronine in the serum of euthyroid children, Klin padiatr .1987;199(5):366-369. Doi: 10.1055/s-2008-1026821

17. Liappis N Schlebusch H Von peryes M Berg I . Reference Values for blood levels of free thyroxine, free triodothyronine and thyronine-binding globulins in euthyroid children method: Lumineseineeenhanced enzyme Immunoassay. 1991;203(2):113115.

18. Zophel K, Wunderlich G, Kotzerke Y. Should we really determine a reference population for the definition of thyroid-stimulating hormone reference interval? Clinl Chem. 2006;52(2):329-330.

19. Fisher DA, Klein AH. Thyroid development and disorders of thyroid function in the newborn. N Engl J Med. 1981;304(12):702712. Doi: 10.1056/NEJM198103193041205

20. Dambal AA, Kashinakunti SV, Manjula R, Gurupadappa K. Thyroid Status in Relation to Age and Gender-A Cross Sectional Study. MRIMS J Health Sciences. 2013;1(2):37-40.
21. Elmlinger MW, Kuhnel W, Lambrecht $H G$ and Ranke MB. Reference intervals from birth to adulthood for serum thyroxine (T4), triiodothyronine (T3), free T3, free T4, thyroxine binding globulin (TBG) and thyrotropin (TSH). Clin Chem Lab Med 2001;39(10):973-979. Doi: 10.1515/CCLM.2001.158

22. Hubner U, Englisch C, Werkmann H, Butz H, Georgs T, Zabransky S and Herrmann W. Continuous age-dependent reference ranges for thyroid hormones in neonates, infants, children and adolescents established using the ADVIA Centaur Analyzer. Clin Chem Lab Med. 2002;40(10):1040-1047. Doi: 10.1515/CCLM.2002.182

23. Khan A, Akhter S, Siddiqui Ms, Ali Khan MM and Nawab G. Effect of age, sex and seasons on the concentration of thyroid and thyroid stimulating hormones The Sciences 2001;1(4):224-227. Doi: 10.3923/jms.2001.224.227

24. Chaurasia P, Modi B, Mangukiya S, Jadav P, Shah R. Variation in Thyroid Hormones level among people of Different Age, Gender and Seasons, Piparia, Gujarat. National Journal of Medical Research. 2011;1(2):57-59. 